Vietnam Academy of Science and Technology
Vietnam Journal of Earth Sciences
http://www.vjs.ac.vn/index.php/jse

\title{
Shifting challenges for coastal green cities
}

\author{
Nguyen Van Thanh1, Dang Thanh Le², Nguyen An Thinh³, Tran Dinh Lan4, Luc Hens*5 \\ ${ }^{1}$ Ministry of Public Security, 44 Yet Kieu Street, Hoan Kiem District, Hanoi, Vietnam \\ ${ }^{2}$ Institute of Administrative Science \\ ${ }^{3}$ Centre for Advanced Research on Global Change, Hanoi University of Natural Resources and \\ Environment, 41A Phu Dien Road, North Tu Liem District, Hanoi, Vietnam \\ ${ }^{4}$ Institute of Marine Environment and Resources (VAST), Da Nang Street, Hai Phong, Vietnam \\ ${ }^{5}$ Flemish Institute for Technological Research (VITO), Boeretang 202, B2400 Mol, Belgium
}

Received 21 January 2017. Accepted 21 March 2017

\begin{abstract}
"Green cities" offer a systematic approach to a significant part of the nowadays urban complexity. The concept dovetails in the "healthy city" idea launched by the World Health Organization, but is equally associated with "sustainable" and "smart cities". During the past decades planning for "green cities" shifted, incorporating new ideas as sustainable development and IT-driven management instruments for smart cities. Contemporary cities continue to face major environmental challenges. Replying to this dynamic context is a main task for cities during the coming decades of the millennium. As most of the (major) cities worldwide are located at the edge of the continents, supporting water-bound activities, they show a significant "blue economy" aspect.

This paper reviews the historical context of the science aspects of "green cities" and the related approaches. Four main challenges for livable (coastal) cities today are discussed, taking into account the continuous changes and the almost permanent transition cities face.

Climate change effects as sea level rise and extreme weather conditions, affect directly coastal cities; providing enough drinking water is a long standing and increasing problem; ports face particular and specific environmental problems which are in need of a tailored management; and sufficient accessible green areas remain of primary concern for any green city. Cross cutting through these issues are among others mobility and sustainable urban design.

These major challenges will necessitate new processes of decision making. Long term planning is essential. This includes among others green infrastructure, systematic investment in natural areas (both on land and in the marine environment), cleaner technology innovations (on water treatment, low carbon emission technology, advanced waste prevention and treatment management, green roofs, and (artificial) wetlands), and the use of smart, IT-driven solutions.
\end{abstract}

Keywords: Energy, water, port management, green building, green city, coastal city.

(C)2017 Vietnam Academy of Science and Technology

\section{Introduction}

In 2008 , for the first time, over $50 \%$ of the

*Corresponding author, Email: Luchens51@gmail.com world's population lived in cities (UN Habitat, 2009) Urban metabolism (including environmental assets as water, air, and soil) consumes about $65 \%$ of the physical resources (food, energy, water, etc.), they mainly attract 
Nguyen Van Thanh, et al./Vietnam Journal of Earth Sciences 39 (2017)

from outside their territory. Cities consume $75 \%$ of the world's energy, and produce $80 \%$ of the greenhouse gas emissions. This causes some $70 \%$ of the total anthropogenic emissions (Varol et al., 2010; Schnitzer, 2015). Cities started to grow in England during the $18^{\text {th }}$ century as manpower immigrated. Worldwide cities grew by $3 \%$ in 1800 , increasing up to $50 \%$ in 2008 . In a business-as-usual scenario, growth rates of $60 \%$ by 2030 and of $70 \%$ by 2050 are expected (Khazaei and Razavian, 2013). Contemporary cities concentrate people and capital (buildings, water-facilities, transport, infrastructure, waste management) and are consequently complex systems with most interesting social and environmental opportunities and risks. On the other hand, cities around the world safeguard an important cultural heritage and work hard on their attractiveness and livability. City centers become pedestrianized, motorized traffic is deviated to ring roads surrounding the city, public transport is on its rise, bicycles reappear, traffic bound air quality improves, and the number of accidents declines. This results in an improved environmental quality, contributing to a better quality of life for residents, workers, and tourists (Chapple, 2015; James, 2015). Cities are supposed accommodating surging populations, while maintaining environmental sustainability, economic prosperity, political engagement, and cultural diversity.

The targets and challenges of the sustainable city of tomorrow are however wider (Chapple, 2015):

- On their environment, cities should go for more green, carbon neutrality, zero waste (in which all waste is used as a resource), clean surface and high quality of drinking water, and optimal use of the scarce soil.

- Socially, cities should offer a healthy environment, respond to changing demography trends (as aging and migration), and provide a safe and equitable (income, opportunities) place. They should be places of inter-individual tolerance, counteract inequality, and fulfill the (changing) housing needs of their residents.

- More than the rural areas, cities have to deal with a fast changing (growing, diversifying) economy. This results in main challenges in economic restructuring as dealing with growing income inequalities and bipolar (high skills, high wages versus low skills, low wages jobs) labor markets.

Cities hosting main ports have a particular role in this respect (Tran Dinh Lan et al., 2014):

- Ports have specific environmental problems on pollution and spills, on treats to biodiversity, on attracting mobility, and as a rule, they have major opportunities operating on a space saving and efficient manner.

- Major ports dominate the economic and social life of their hosting city.

- Cities with main ports have an outspoken cosmopolitan character, where a variety of nationalities and cultures provide added value. However, they also have to fulfill the specific housing needs of their population.

- Ports have a key role in the economic transition to the next generation. They are crucial in implementing both the green (Griggs et al., 2013) and the blue, marine based economy.

These different aspects on what cities are expected to realize during the decades to come, are combined in visions on the city of tomorrow, aiming at establishing a better, safer, and more equitable place to live for the citizens. Although no single, generally accepted definitions exist in this domain, major components of this multidisciplinary and integrated vision entail:

- Healthy cities: Already in the 1970ies WHO Europe put emphasis on a qualitatively high social and physical environment as a prerequisite for human (animal and ecosystem) health. The necessity of such an approach gradually became more evident e.g. as a result of the different morbidity and mortality patters between cities and their surroundings. The incidence of so called "civilization diseases is only an exponent of 
this trend: 2 people out of tree suffering from diabetes live in cities; its incidence and risk of type 2 diabetes is affected by particulate pollution in the air; multiple and complex links exit between "urban diabetes" and climate changes (IDF, 2015). WHO invested in developing the concept of the "healthy city" and spreading the idea through initiatives with academia and other stakeholders.

- "Green cities" emerged from the challenge of turning the weaknesses of postindustrial cities (pollution, urban degradation, consumptive resource use) into opportunities. They focus on a sound environment in which accessible green is a main component, next to carbon neutrality, and outstanding environmental management (including among others zero waste) and services (Lucarelli and Roe, 2012).

- "Sustainable cities" focus on combining environmental, social and economic aspects. They have an equitable and inter-generational outlook, aiming at reaching more livable communities. A committed definition of a sustainable city reads as: "a sustainable city is one in which the conditions under which I live make it possible that my children and the children of my children will live under the same conditions" (Castel, 2010). The concept is most in depth to the "local agenda 21", an international initiative of local authorities on implementing Rio's Agenda 21 (UN, 1992). The Rio+20 conference put emphasis on the opportunities of a green economy, in particular also at the local level (UN, 2012). In urban planning, sustainable cities are the core target of the "New urbanism" movement (Godschalk, 2007). Concepts related with the sustainable city idea are the eco-city (an urban system reflecting natural ecosystems to an as much as possible and reasonable extent), the carbon neutral (releases as much $\mathrm{CO}_{2}$ as it fixes), the compact (referring to the functional and physical densification), the zero-waste (where all waste is used as a resource), and the ubiquitous eco-city (U-eco-city in which information and communication technologies have a significant impact, and consequently is closely associated with the "smart" city) (Hassan and Lee, 2015).

Box 1: The colors of urban development.

"Green cities" refers to some extent to the green urban morphology with a lot of parks, other plants, and trees mediated elements. Today a green city also strives towards carbon neutrality and zero waste production.

More fundamentally, green cities entail terrestrial ecological features and ecosystems.

"Blue cities" refers to the aquatic urban character of coastal and estuarine cities. For (almost) all coastal cities the marine aspect is trivial. The blue character of a city refers also to rivers, lakes, urban wetlands, and other water components of the "natural" infrastructure of cities.

As the green city infrastructure, the blue aspects of the city take advantage of natural structures and ecological processes, making them more flexible than the grey options (see below). The blue economy refers to trade and economic activity which is bound to these blue city elements.

"Turquoise" Not all elements of the city can be classified as convincingly green or blue only. Wetlands or inner city lakes for example often have a combined terrestrial and aquatic character. Their green-blue appearance is called turquoise.

"Grey" infrastructure is engineered, entailing houses, water distribution and treatment, waste management, and energy. Previously the grey infrastructure was closely related to the concept of the "sanitary city" when less was known about the environmental, social, and climate change impacts of the physical design of cities. 
Nguyen Van Thanh, et al./Vietnam Journal of Earth Sciences 39 (2017)

- "Smart cities" are the more recent policy synthesis of how livable cities should look like in the future. Combining the three foregoing concepts, they see efficiency as an essential component. This might be reached, at least in part, by innovative technological developments (Avin and Holden, 2000; Giffinger et al., 2007; Taghvaei, 2013). They rely on ecosystem services of an equilibrated urban environment. Smart city incentives deal with natural resources and energy, transport and mobility, buildings, quality of life, government, economy, and people (Neirotti et al., 2014). They are characterized by economic, social, environmental, urban, demographic, and geography variables. They should lead to an improved city management, in favor of the quality of life of the citizens. Although a widely shared definition of a "smart city" is not available, "Smart" means innovative, skilled inclusive and sustainable. At the limit the smart city is a build environment where any citizen can use any service anywhere at any time through information, optimization, and communication technologies (ICT) (Lee et al., 2008). When it comes to the increasing energy consumption of the growing population in densified environments, the above coincides with the improvement of energy utilization and efficiency, and relieve of the energy related pollution (Akcin et al., 2016). Realizing this supposes critical decisions in a timely manner by coordinated individuals or groups, supported by real-time computation of data relevant to the decision (Jung et al., 2009). ICT applications in E-cities show a multitude of aspects ranging from public bikes management (eventually locked with a proper app on the mobile) as part of green urban transport, supporting trade among others of small and medium-sized downtown shops, guidance for foreigners visiting the city, and green cards for ordering and sending products and parcels, to the surveillance of children and elderly who suffer from the neurodegenerative Alzheimer disease. Over-all contemporary urban technologies allow improving the economic and environmental dimensions of the city. The eco-city of today is based on a smart electricity grid, and water distribution system, contributing to energy saving and efficiency, recycled water supply and sustainable transport. This new paradigmatic, multidimensional perspective integrates interventions of sustainable, green and healthy cities.

The above analysis shows that the concept of "green city" in particular for coastal cities is dynamically changing over time and resulting in an increasing complexity. This paper aims at reviewing core elements of the green city of tomorrow. It focusses on key elements of energy transition in green cities and problems associated with water consumption and quality. It goes into more details on the port-urban interrelationships in main coastal cities, including accessible green areas and "green building". These are important challenges for green cities with a shifting content. However they are not the only challenges. As an illustration of this latter the contribution looks in the changing paradigm of the built urban environment. For each of these four aspects both general elements and Vietnamese particularities are discussed. The conclusion points to the consequences of these challenges for contemporary urban management.

The underlying hypothesis is that during the years to come cities should take the lead in the energy transition societies worldwide face today. A move towards green building has the potential significantly contributing to this transition. Moreover cities have to deal urgently with the fast increasing shortage of drinking water. Port cities face the additional challenge integrating the specific port activities in their "green planning", contributing in this way to a sustainable "bleu economy".

\section{Materials and Methods}

This review is based on the international scientific literature. For each of the four main challenges dealt with in this paper (energy transition, drinking water, green buildingwhich frames in the natural character of the 
city, and ports) the most recent publications were identified on Google Scholar by combining the denomination of each area with the terms "coastal green city". The most relevant papers for each area were selected.

This information was completed with recently (last 6 years) published texts and research books. This provides the paper with a more relevant master level and advanced studies character.

Two meetings organized in Vietnam provided a significant part of the Vietnamese information:

National workshop on green growth. Green port city. Hai Phong, March 26-27, 2014.

International conference on public administration of the sea and islands: Issues and approaches. Hanoi, December $2^{\text {nd }}, 2016$.

Whenever the text refers to the opinion of experts, this is indicated as such.

\section{Results}

\subsection{Energy transition}

One might consider cities as environmental systems with inputs of energy and resources, an urban metabolism, and waste and pollution streams as outputs. One of the consequences of such a systems analysis is that in particular (but not exclusively) from an energy point of view, urban ecosystems are parasites. They depend on the stocks of concentrated energy, provided by natural, semi-natural, and mandominated systems (Vadineanu, 2001). This has major consequences for the sustainability of cities.

Energy is essential for socio-economic welfare at all environmental scales, from local to global. Currently most of it is produced in an unsustainable way. Fossil fuels (oil, coal, natural gas are the basis of over $90 \%$ of the global commercial energy production, while sustainable resources as solar, water-bound, wind (both on land and off-shore) or geothermal energy, are underused. In combination with the safe nuclear energy myth, this results in fast increasing $\mathrm{CO}_{2}-$ emissions which, in combination with other greenhouse gasses in the atmosphere, have been causally linked with climate changes. The physical environmental aspects as melting polar and mountain ice, but also temperature increase, extreme weather conditions, as drought and heat waves, and storm incidence and intensity, are today changing faster than any model predicted 20 years ago.

In particular coastal areas face risks related to climate changes (IPCC, 2007, 2014; World Bank, 2010). This definitely applies to Vietnam where coastal communities are vulnerable to tropical storms (Dasgupta et al, 2009; Nguyen et al., 2011; MONRE, 2012). The effects are related to Vietnam's over $3,000 \mathrm{~km}$ long coastal line where the majority of its economy is realized. Moreover, urban development bordering the sea and the banks of the main estuaries, and behind the dune ridge which flanks the beaches, the agricultural and densely populated lowland is most vulnerable to floods affecting the human populations. The coastal area of Vietnam faces three main hazards of which the combined effect is likely associated with climate changes (IPCC, 2007, 2014; UNDP, 2007; Dasgupta et al., 2009): drought, sea level rise, and extreme weather conditions. On their turn these primary effects cause floods and erosion and affect the risk of accidents on sea. Among these, accidents with oil and natural gas production and shipment attract regular attention. More details on the impacts of recent typhoons in northern Vietnam are provided in box 2 .

Needless to stress that the infrastructure of ports, their associated activities, and port cities as a whole are particularly vulnerable to sea level rise and storms.

All these climate change related hazards are increasing in coastal areas. Average global losses in 2005 are estimated to be approximately US\$ 6 billion per year, increasing to US\$ 52 billion by 2050 . This points to the necessity investing in prevention measures and to prepare for even larger disasters than the ones we face today (Hallegate et al., 2013). Both the prevention 
Nguyen Van Thanh, et al./Vietnam Journal of Earth Sciences 39 (2017)

and restoration activities necessitate increasing parts of the urban and other budgets. Quantitative estimates on how much are difficult to provide in view of the uncertainty linked with the factors under discussion.

Box 2: Typhoon related inundations in northern Vietnam in 2014 and 2015

Irregular typhoons occur increasingly more frequently in coastal areas where most of the Vietnamese cities are located. In 2014, two typhoons (3-KALMEGI and 4-SINLAKU) landed and affected the two coastal cities of Hai Phong and Quy Nhon, causing storm surges of $1.1 \mathrm{~m}$ and $0.4 \mathrm{~m}$, respectively (MONRE, 2015). Heavy rain fall caused floods and inundations both in the hinter land and in the coastal cities. In 2015, heavy rains in Quang Ninh, including the coastal cities of Ha Long and Cam Pha lasted for about a week (25 July to early August) with rain fall reaching up to $1,000 \mathrm{~mm}$ in some places, causing floods, inundation, landslides combined with serious damage to human lives (17 dead), hundreds of houses destroyed, 4,863.2 ha of rice and other foods lost, 2,258 marine culture cages damaged, transport infrastructure destructed, etc. Losses were estimated at 2,700 billion VND (MONRE, 2015). Sea level rise may cause serious inundations in the coastal city of Hai Phong. 3 scenarios of sea level rise have been published by the Ministry of natural Resources and Environment (MONRE, 2009) of Vietnam. The commune of Vinh Quang (Hai Phong) is expected to be inundated for $<0.5 \mathrm{~m}$ for $34 \%$ of its surface (Vu Thanh Ca et al., 2010). Hai Phong as a whole might lose one third of its area with evidently major consequences.

Moreover, because of the inertion which is characteristic for human adaptation, and our minimalistic successes in establishing worldwide mitigation and adaptation policies for this global problem, also its impact on poverty and social inequality, point to the imperatively urgency of a transition towards sustainable energy sources. An example and non-limitative list of mitigation and adaptation opportunities is provided in table 1 . The table illustrates the wide action domain which is covered, ranging from sustainable energy projects, over flood risk management, and carbon sinks, to education. In complement to these general action areas, in particular coastal and island cities need focusing on measures responding to the local climate change induced needs.

Table 1. Selected examples of mitigation and adaptation strategies cities might adopt (Camarsa et al., 2010)

\begin{tabular}{|c|c|}
\hline Mitigation & Adaptation \\
\hline $\begin{array}{l}\text { Green public procurement supporting the market for gr } \\
\text { products and services }\end{array}$ & imate chang \\
\hline Introducing sustainable modes of transport & Management of risks to buildings and infrastructure \\
\hline Promoting improved energy performance of buildings & Flood risk management \\
\hline $\begin{array}{l}\text { Planning for sustainable development (e.g. reducing } \\
\text { commuting) }\end{array}$ & Management of water supplies \\
\hline $\begin{array}{l}\text { Promoting education on climate change and sustainable } \\
\text { development }\end{array}$ & Management of coastal erosion \\
\hline Promoting local renewable energy projects & $\begin{array}{l}\text { Enhancing the resilience of species and habitats through } \\
\text { nature conservation actions }\end{array}$ \\
\hline Development of green space and carbon sinks & $\begin{array}{l}\text { Ensuring healthcare services are prepared to deal with } \\
\text { health risks arising from heat waves or new vector-borne } \\
\text { diseases }\end{array}$ \\
\hline $\begin{array}{l}\text { Promoting and encouraging more sustainable patterns of } \\
\text { behavior among citizens and businesses }\end{array}$ & $\begin{array}{l}\text { Preparing for and facilitating the integration of migrants } \\
\text { from areas worst affected by climate change }\end{array}$ \\
\hline
\end{tabular}


Cities should also go beyond mitigation and adaptation to climate change. It is of core importance they develop urban climate resilience initiatives. Resilience is more broadly defined than mitigation and adaptation, such that it involves the various systems which affect the ability of the city to anticipate, absorb, and reorganize itself in relation to both known and unknown threats (Meerow et al., 2016).

At current rates of consumption it is estimated that during this $21^{\text {st }}$ century, we shall move into a period of global energy scarcity. Technical innovations in the production, transmission, distribution and consumption will likely not replenish the nonrenewable reserves. In contrast, renewable energy sources are candidates to meet the (qualitative and quantitative) energy requirements of the future in a sustainable manner. They emerged indeed having many environmental and social advantages when compared with fossil fuels, and they are definitely economically feasible. However, solutions should go beyond the current use of silicon based photo-voltaic panels which use more energy during their construction than they can generate during the utilization phase of their life cycle. In contrast, wind intelligently used solar, ocean currents and photosynthesis are sufficient to meet the energy needs of the generations to come (De Las Heras, 2014). Next to a fundamental change in energy sources also a move to a more efficient use of the available energy in unavoidable. For cities and their regional hinterland the use of "smart grids" will prove advantageous. For households awareness raising, education, and other socio-ecological instruments are most useful.

Apart from this technical transition to renewable, clean energy sources and increased efficiency, other policy options should be taken. Of particular importance are the zerocarbon and carbon-negative concepts (Kennedy and Sgouridis, 2011). Zero-carbon or carbon neutral cities store in their green belts as much carbon as they release through their urban metabolism. Zero carbon cities established an active policy on expanding their green spaces on par with a $\mathrm{CO}_{2}$-reduction-emission policy of pedestrianization, energy savings, and restoration of natural life cycles. Carbonnegative cities move a logical step forwards as compared to carbon-neutral cities, retrieve more $\mathrm{CO}_{2}$ from the atmosphere than they emit, and consequently act as a storage center of carbon. A related concept is a low carbon economy, which primarily includes less electricity consumption with an appropriate and limited greenhouse gas emissions. This should be realized with technical and economical cleaner technology interventions, coupled with an appropriate and targeted policy. Current research shows that both zero carbon and carbon negative solutions are possible.

As illustrated in Figure 1, four components are essential in establishing zero/low carbon cities:

Addressing low carbon agents as individuals, households, small and mediumsized organizations.

Target low carbon economies that use low and zero amounts of carbon energy, and consequently emit less pollutants.

Promote and build low carbon infrastructures such as buildings, and roads. Invest in public transport.

Develop low carbon urban spaces. This necessitates an adapted land use planning, but also social instruments promoting interactions between people.

Figure 1 illustrates how these four components are related with the energy inputs, storage, and emissions of the urban ecosystem. In a zero-carbon city the $\mathrm{CO}_{2}$ generated needs to be stocked in the vegetation or captured in $\mathrm{CO}_{2}$ storage facilities.

The zero-carbon emissions idea is increasingly appealing to cities. In 2016 a record number of 533 cities worldwide, representing 621 million citizens was monitoring and disclosing data on their $\mathrm{CO}_{2}{ }^{-}$ 
emissions. The Asia-Pacific zone e.g. has seen a rise of nearly one third of the participating cities since 2015. First time disclosers in 2016 include Kuala Lumpur (Malaysia), Guangzhou (China), and Bangalore and Kalkota (India), (Colombo, 2016).

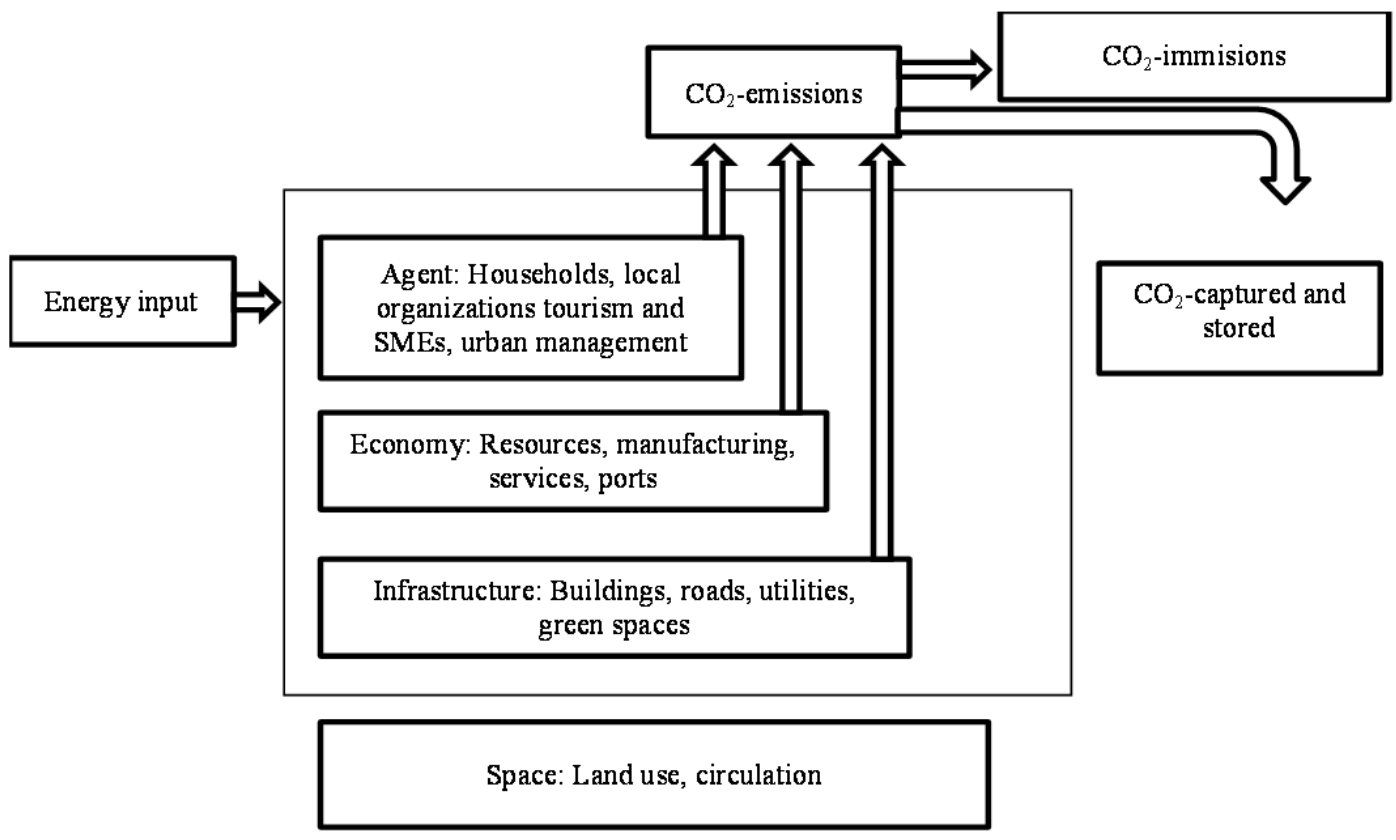

Figure 1. Core dimensions of green cities as an input-metabolic-output model (modified after Kennedy and Sgouridis, 2011)

Next to their dense energy consumption and the related high emissions of greenhouse gasses, cities have a second important driver to act on the subject: The urban heat island effect. This is one of the best established, and long known features of urbanization. The phenomenon refers to the increased urban surface temperature in cities, which is more intense than in the surrounding non-urban regions. The effect can be $6^{\circ} \mathrm{C}$ in a small Mediterranean city during the day in summertime, and $3.8^{\circ} \mathrm{C}$ during the nocturnal hours (Vadoulakis et al., 2013). Moreover the effect is limited to the first $300 \mathrm{~m}$ above the ground surface. The urban heat island is enhanced by temperature extremes which are climate change related. The combination of heat islands and heat wave events, may result in many deaths and a good deal of discomfort (Knowlton et al., 2007). It has been estimated that urban planning giving more attention to increasing urban greenery, reducing motorized traffic, and improving building design, a cooling effect of $4^{\circ} \mathrm{C}$ can be achieved (Mueller et al., 2016). However its social significance and implications for environmental justice, and urban infrastructure should be subject to more research (Huang et al., 2011).

\subsection{Fresh water}

Fresh water management is most important in cities. However, fast growing megacities are skating on water-related problems as pollution, eutrophication, missing wastewater treatment, and severe scarcity of clean water (Hinrichsen, 1998; Haase, 2015). Cities have a complex water cycle with supply, sewage, and storm water as main elements. In cities both direct and indirect use of water matters. Direct aspects relate to the soil cover which is cities is more extended as compared to rural 
areas. This contributes to a fast evacuation of rainwater, preventing it from percolation through the soil and replenishing ground water reserves, which are under threat by an increasing demand for water supply by households, agriculture, industrial, recreational, and greening urban activities. Moreover the fast removal of the rainwater affects the quality of the groundwater. Direct use of household drinking water is limited to about $1 \%$ of the total water consumption.

Indirect use of water exceeds the direct water use. Food production necessitates high amounts of water. Agriculture accounts for $70 \%$ of water use. Different foodstuffs and production systems have differential impacts on water: With 15.000-70.000 liter of water per kilogram, meat has the greatest impact, vegetables have a smaller water footprint. Cities import most of their food from the neighboring or more remote rural areas. Actually, this indirect use of water should be put on their account.

Realizing the combined importance of direct and indirect water use resulted in establishing the concept of the water footprint (Hoekstra and Chapagain, 2007). Moreover the world faces a water quality transition which might be handled by the prevention of water contamination, removal of pollutants (using a battery of water treatment technology), and more efficient coping with excess of water in case of disasters. Extreme environmental events contribute to catastrophic damages in urbanized areas across the world. For politicians, architects, sociologists and geoscientists protecting people and cities has become a paramount task.

The local level is increasingly important in addressing these water issues. Urban water management and sanitation infrastructure have to deal with the imminent water scarcity, and varying and changing rainfall patterns. Moreover coastal cities face rising sea levels. Cities are supposed linking sanitation, drainage, drinking water supply, and wastewater in a coordinated approach, the target being to deliver high quality water to all citizens at an affordable price (Camarsa et al., 2010).

Over-all cities need shifting away from the traditional, fragmented urban water management, which prevails today. They should move towards a more integrated approach based on the water cycle. This policy should deal with the problems of contemporary issues and the future needs (Diaz et al., 2016). This goes beyond using the grey-and wastewater, and integrates among others the use of ground and rainwater in the urban water strategy, but also deals with water security and quality, drinking water, sanitation, infrastructure, climate robustness, biodiversity, attractiveness and perception, and governance, including public participation.

In coastal cities water winning and retraction is a critical issue because of the risk of salt water intrusion.

Dealing with fresh water problems in cities entails a variety of aspects:

Blue infrastructure includes wetlands, ponds, waterways, and floodplains (acting as buffers in case of inundation).

Green infrastructure includes accessible greenways and corridors. More vegetation regulates less runoff, more infiltration and recharge of the water table, and less urban heath islands. It contributes to less pollution, e.g. from particulates.

Most of these global considerations apply to Vietnam, a country which highly depends on, among others, agricultural irrigation water and increasingly saline groundwater. The shortage of supplied water in general and drinking water in particular, affected many coastal cities, particularly in the central provinces Quang Tri, Binh Dinh, Khanh Hoa and Ninh Thuan (MONRE, 2015).

Cases of anthropogenic water pollution in rivers that supply fresh water to coastal cities/provinces are documented. For example, downstream of the Red River in the Nam Dinh province the water is locally polluted with organic matter and nutrients at values close to or exceeding the Vietnamese standard (Figure 2). 
Figure 3 shows the increasing percentage of the population in the coastal city of Hai Phong supplied with drinking water during the period 2009-2013. This is an indicator for the increase in the amount of supplied potable water in spite of the most convincing efforts of the city authorities positioning Hai Phong as a "Green city".

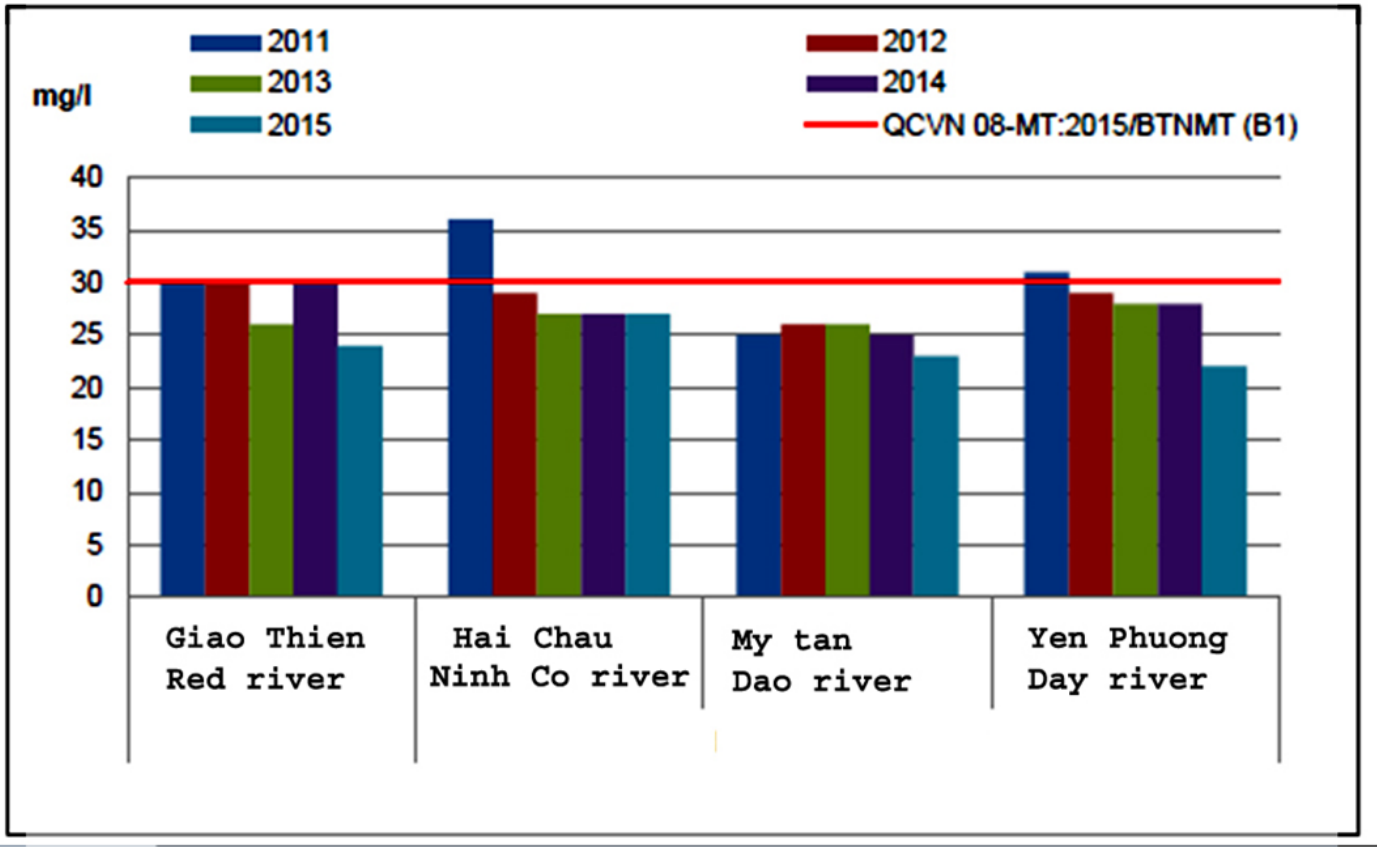

Figure 2. COD concentration in water of Red River tributaries in Nam Dinh province, 2011-2014 (MONRE, 2015)

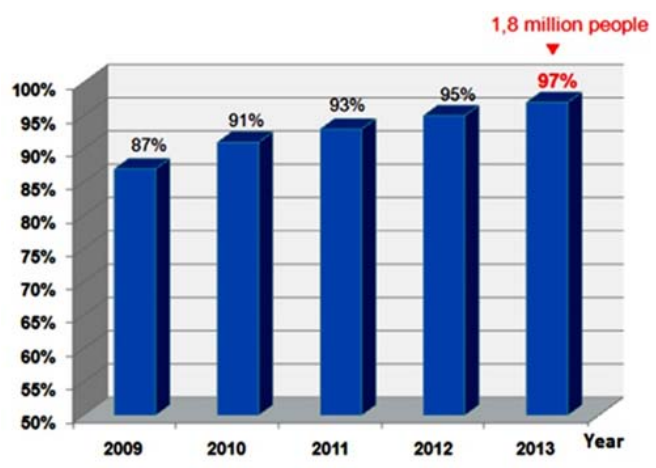

Figure 3. Percentage of the population in Hai Phong with potable water supply (Nguyen Van Thanh, 2014)

\subsection{Green ports}

Worldwide most cities are located at the edge of the continents or along the banks of the main estuaries. Most of them are proud on their "waterfront", which, worldwide attracts local people and tourists. Many of these cities host ports of variable size, but all of these (different types of) harbors have significant impacts on the local economy and the urban quality of life (QoL). The development of city-port relationship shows the importance of ports to the local economy of a coastal city (Boulos, 2016). Ports are major enterprises and as such they have as a rule a profound impact on both their direct, port-bound environment and on their (both marine and hinterland environment.

Specific, direct environmental impacts of ports entail:

- The water in and around the port is polluted with oil and chemicals. Both problems originate in the normal operation of the port (minor spills), which is a source of chronic pollution, but also in massive spills resulting from occasional main (intended and 
accidental) incidents. Part of the oil pollution also originates from the treatment of water contaminated with oil. The water of the Cam River downstream of the port of Hai Phong contained $1.62 \mathrm{mg}$ of oil per liter water in 2007 (Duong Thanh Nghi et al., 2014). Moreover in and near ports high concentrations of bacterial contamination were found.

- Water soils act as a memory of the water pollution and contain higher concentrations of PCBs, heavy metals, butyltins, and a wide series of hydrocarbons including pesticides. In 205 the sediments in the port of Da Nang showed total concentrations of butyltins of $22.3 \mathrm{ng} / \mathrm{g}$ dry weight. Of this total value the endocrine disrupter tributyltin accounted for $8.4 \mathrm{ng} / \mathrm{g}$ dry weight (Do Thi Thu Hong and Tran Dinh Lan, 2014).

- Waste from the in-port operations and the waste collected from the ships totals variable amounts which are most significant in major ports. Huge amounts of waste result from dredging activities. Their disposal might result in important environmental consequences. Next to waste from dredging, ballast water from ships might offer particular problems as it might introduce align species in new environments.

- Ship recycling (dismantling old and decommissioned ships enabling the reuse of valuable materials) serves a typical port bound activity with significant environmental impacts. This activity is a major supplier of steel and an important part of the economy of port cities in many countries. The recycling of scrap also reduces the need for mining which as a rule has important environmental and social impacts. Ship recycling is a vital part of the circular economy - which supports to minimize waste and recycle materials. On the other hand the pollution caused by scrap reflects the pollution in the harbors: Heavy metals, petroleum and non-oil associate hydrocarbons are found in the (water bottoms) of the ship recycling yards. The activities are, among others, linked to carcinogenic air pollution, asbestos exposure, and disruption of the water (micro-) organism communities. Costs of upgrading these sites of intense pollution vary according to the type of contamination and the size of the brownfield area, but amounts to millions of US dollars. Likely a more appropriate recycling targeted ship design might significantly reduce these costs, prevents pollution, and is environmentally more sustainable. (Science for Environment Policy, 2016).

- As any other organization, ports use energy, water and materials. An environmental management targeted to less consumption of resources and less pollution of these streams is indicated (Le Xuan Quynh, 2014).

- Port activities generate massive amounts of traffic, among which these of dangerous goods. An appropriate intermodal mix of transport (truck, inland waterways, and railway), transport planning, and optimization of transport loads might alleviate the environmental impacts.

Land use: Ports with an increasing throughput, in growing economies, are in constant need of land replying to their increasing activities. In general they find this land in the industrial, agro- and aqua-cultural, recreational and (protected) natural areas of their periphery. For port cities the increasing role of the peri-urban space (between the port and its rural-urban setting) is of increasing importance for recreational and leisure purposes by urban and rural dwellers (Zlender and Thompson, 2016). A deliberate policy of densification of the port activities might reduce the latent need of land in an increasing economical context.

These environmental problems in ports and port areas can be badderessed using high quality, certified environmental management systems. Because of their complexity and the specificity of some of these problems, specific processes and procedures adapted to ports have been developed. Examples of environmental port management in Hai Phong, Vung Tau and Da Nang are provided in box 3 . 
Box 3: Environmental management at the ports of Hai Phong, Da Nang and Vung Tau

The construction and operation of the ports in Hai Phong impacts the environment. A series of measures is proposed aiming at reducing the negative impacts, limiting the exposure to pollutants, to enhance the capacity of the port, and to act on emergency situations. The target is to define mitigation measures for the identified environmental impacts. These should be applied on a life cycle basis, during all the phases of the master plan: construction, operation and during demolition. The mitigation measures combine technological improvements and adjustments, with managerial procedures. The measures are categorized according to the impacted environmental compartment.

For the port of Hai Phong the following areas of environmental management were identified (Duong Thanh Nghi et al., 2014):

- Limit the use of land which is important for biodiversity when the port facilities expand.

- Construction activities of specific port facilities (warehouses, quays) should not hamper the safety and health of professionals and locals.

- Limit changes in water turbidity during dredging and dumping operations.

- Limit the run-off and environmental spread of bulk goods as coal, phosphate ore, sulphite, and bauxite, just mentioning these examples.

- Act on waste water from ships. Pay specific attention to invasive species.

- Limit pollution from ship construction and repair.

- Prevent spills of oil and chemicals both in the port and off shore.

- Develop environmental monitoring and study environmental impacts of port activities on the environment.

Environmental issues the Da Nang port faces include: degradation of water quality, air pollution and waste management. The water quality degrades as a result of oil pollution, inorganics and heavy metals. Moreover, the air around Da Nang port is polluted by dust caused by the cargo activities (especial of wood-pulp and white sand in the Tien Sa port). Environmental management in Da Nang port is still weak, although parts of an EMS are under development. Waste management and prevention of environmental pollution are challenges for the environment management. The port has insufficient capacity dealing with these issues by itself. The problem is addressed in an efficient way with the support of environmental experts, and international collaboration.

The rate of increase of the cargo throughput in the southern port of Vung Tau is spectacular, and on par with the fast economic development of the wider Ho Chi Minh region. However, the resulting effects on the environment, biodiversity and water quality are insufficiently addressed by the port. Port bound environmental problems, include disposal of rainwater, release of untreated domestic effluents, the absence of collection and treatment facilities for on board waste water and solid waste, a partially functioning network for oil spill responses, and chemicals as paints and rust discharged in the water. Moreover the inspection and control actions by the port authorities face significant difficulties. A sustainable seaport in Vung Tau necessitates strategies integrating environmental protection in the general plan. An environmental management system (EMS) is mandatory for the port. This will benefit the port and provide Vung Tau with a pioneer role in environmental protection in Vietnam (Tran Dinh Lan et al., 2014).

Port activities however also impact the wider area surrounding the port, both on sea and on land. On land they are inconstant interaction with their hosting city, and its neighboring (agricultural, industrial, recreational) areas. Managing these aspects necessitates a structured involvement of the complex target groups interacting with the 
(expanding) port activities: Farmers, competent authorities, city, the urban population as a whole.

As much as with the mobility issues on land, port activities are associated with the routes over sea. Shipping is a significant source of greenhouse gas emissions, accounting for an estimated $2.7 \%$ of the global $\mathrm{CO}_{2}$-emissions in 2013 (Ülpre and Eames, 2014). Moreover the combustion of heavy diesel oil releases $\mathrm{SO}_{\mathrm{x}}$-compounds which contribute to acidification, $\mathrm{NO}_{\mathrm{x}}$ and particulates, which are harmful for the marine biodiversity and human health. Accidents on the sea (mainly oil spills and to a lesser extent also spills of non-oil chemicals) might have most important environmental impacts sometimes over large areas. The issue exceeds the media sensitive clean-up of e.g. floating oil or oil slicks deposited along the beaches. It is mainly a matter of being prepared for the next spill, so that the impacts can be limited. Part of this prevention policy is the concentration and the geographical distribution of the sea-routes, and in the establishment of marine protected areas. Part of the prevention responsibility in the open sea is assumed by the International Maritime Organization, but it is evident that also ports and their competent authorities are instrumental in this respect.

\subsection{Green building}

As mentioned in the introduction to this paper, cities attract major amounts of (environmental) resources from their nearby or more remote hinterland. By the end of last century, $70 \%$ of the non-fuel materials in the US were used for construction. The construction industry is responsible for $40 \%$ of the energy consumption and the $\mathrm{CO}_{2}-$ emissions in the country. Also the increasing demand for housing facilities, the growing suburbs of inappropriate settlements and the increasing housing prices put the urban system under continuously increasing pressure. Not only is the construction phase important. Buildings in industrialized countries are the greatest energy consumers. $40 \%$ of the energy consumed is used for heating, cooling, lighting, and powering machines and devices in buildings (Henn and Hoffman, 2013). The real challenge is making the nowadays city and the way we live in it more sustainable.

Suggested solutions are multiple and varied:

- Sustainable building: Applies the concepts of sustainable development (environmentally sound, societally desirable, and economically feasible in the building sector). New construction technologies and new building components would allow to reduce the ecological load of buildings to a fraction of its present value. However, the problem of making our building stock more sustainable is only to a minor extent a technical one. The required change of technologies can only be managed by simultaneously taking into account technical potentials and their social context. Consequently sustainable buildings use limited amounts of energy and high quality drinking water, cultivate an high standard of indoor air quality, advanced lighting, limited and definitely no disturbing noise, contribute to a high satisfaction of the inhabitants, and are part of the zero waste activities of the city. (Malcolm, 2004).

- Bio-regions and bio-urbanism: Merging nature and culture, combining living, recreational and economic values of the city. The eco-city concept is closely associated with this approach.

- Rural-urban industrial ecology: Cities attract both their human and their physical resources from their (near and more remote) surroundings. Sustainable cities should strive towards more autonomy and self-sufficiency. Apart from maximizing green spaces, using 
e.g. green roofs (Olivien et al., 2013), and generating its own food, cities should pay more attention to recycle and reuse the materials they attracted from abroad.

- Transport-city structure nexus: From a mobility system which causes increasingly car congestion, cities should move towards compact, dense, vertical structures with multiple uses. Pedestrians should be given priority over cars. Modelling work showed that compact development reduces the distances travelled, the energy use and the $\mathrm{CO}_{2}$-emissions.

- Design: Sustainable buildings are energy neutral (rely on the energy they capture from abroad), while the materials fit within a cradle-to-cradle (zero waste concept), and fit within the ecosystem.

- Green architecture: Provides energy neutral houses and buildings which suit humans and their activities, and restore the balance with nature. Green architecture shows specific aspects such as green roofs (and facades). Constructing a "roof garden" on solid roofing membranes is expensive, but not only contributes to a more attractive urban environment and biodiversity of local plants, insects and microorganisms, but also regulates the indoor temperature, increases the energy efficiency of the buildings, and attenuates air pollution and the heat island effect city-wide. Green roofs are an essential element of sustainable building.

- Special attention should go to buildings with specific functions, in areas which are not familiar with incorporating the concept of sustainable building. Health care buildings, hospitals in particular, offer an example: They are the second most energy-intensive type of "commercial" building as a result of their 24 hours operational activity, concentrate people, and have to pay special attention to the quality of their indoor environment. Next to their medical infrastructure, they run a significant "hotel" and administrative section. They should take more than average advantage of applying up-to-date energy- and waterefficiency technology, life cycle cost analysis, and aesthetical quality of their buildings (Castro et al., 2015). In short, they should be the first ones lining up for healthcare without harm to the environment, also when it comes to heathy buildings (WHO, 2016).

- For the city sustainable buildings are part of the urban design, which is addressed by architects, landscapers, and planners since the 1950ies. However, the new urban challenges are adapting to nowadays economic restructuring, mass migrations, and climate change. Contemporary urban design is therefore more than ever before a multidisciplinary and multi-stakeholder approach involving civil society, community actors, environmental experts, engineers, and city managers (Childers et al., 2015). At its environmental side urban design entails greenfield (incorporating natural elements), greyfield (build to resist environmental hazards), and brownfield (reuse of decontaminated polluted sites).

In conclusion, urban green building should contribute to a diversified economy and an increased resilience in different steps:

By restoring and regenerating biotopes, natural cycles and wildlife in the cities.

By integrating blue and green aspects of the economy, brownfield (contaminated sites) development, and using sustainable energy sources.

By eliminating cars and giving priority to pedestrians.

\subsection{Green spaces}

Urban green space availability has become more and more important in eco-city planning because of its importance for the urban residents' wellbeing (Kabisch et al., 2016). Green cities "consider green urban elements as a physical structure forming an integral part of the city (e.g. green corridors, or green belts), as a network of "green" elements, as a 
physical infrastructure which has a role in water management, the urban micro-climate and in biodiversity, and also as a social infrastructure for leisure, relaxation, human interaction, and other social activities." (Duhem, 2005). Green spaces as common goods take a variety of appearances ranging from fallow land, over parks and road separations, to urban woodlands and forests. Their common characteristic is that they are localized within the city boundaries. They absorb $\mathrm{CO}_{2}$ and enhance the resilience and climate change mitigation and adaptation capacity of the city. Providing habitats to local plants and animals, they contribute to the urban biodiversity. They provide recreational opportunities for city dwellers and the inhabitants of the neighboring villages. They clean the air, reduce noise, and regulate the urban ecosystem. WHO recommends that urban dwellers should live within $300 \mathrm{~m}$ of a green space greater than 0.5 hectares in size. Citizens frequently visiting and using urban green areas have less medical complains, payless visits to their doctor, stay shorter periods in hospital when hospitalized, take less medical drugs, and feel more healthy. In the coastal city of Barcelona (Spain) almost 3000 deaths (coinciding with $20 \%$ of the yearly mortality) are premature, and would be preventable if residents lived in urban environments that met international exposure recommendations for physical activity, noise, heat, and access to green spaces. If these premature deaths were prevented, urban residents could expect to live on average, 360 days longer. This supposes reducing motorized traffic, promote active (e.g. bicycling) and public transport, and provide adequate green space (Mueller et al., 2016). In many cities green spaces are under pressure and their area is declining. A sustainable city provides ample green space to its inhabitants.

\subsection{Other aspects}

The aspects governing the quality of life in cities are not limited to the main challenges discussed above. In this contribution the focus was mainly on the physical environmental aspects. Consequently social and cultural aspects in which cities excel remained underlightened. Education, monuments, museums, migration and safety provide examples.

In the previous discussions mobility and traffic infrastructure were cross-cutting. When it comes to new energy patterns, the build environment, or port issues, mobility is mentioned. The conclusion on a transition towards pedestrianization and limited access to city centers for (privately owned, old) combustion engine cars and vehicles) appears invariably. This option has unexpected health consequences. There is few doubt that the emissions of in particular noise, NOx and particulates from cars affect human health $(\mathrm{Vu}$ Van Hieu et al., 2015). However recent research showed that the main health benefits from reduced traffic-related pollution in cities is from increased physical activity as people walk, cycle, and move to catch the public transport.

\section{Discussions}

Issues on urban sustainable development are increasingly of critical importance around the world. In particular polluted, physically, societally, and economically disadvantaged cities deserve attention.

This paper anchors on five first order issues for the livability of the city of tomorrow:

The energy transition: Both the nature and the quantity of the urban energy consumption are at stake. Carbon based energy sources are the main contributor to climate change, while the effects are most intensively felt in coastal cities. The enormous amounts of energy a city imports, illustrate its parasite character. Cities should strive towards the use of sustainable energy forms, they maximally produce themselves from solar, wind, water, and soil.

Fresh water: Sufficient supply of high quality drinking water offers increasingly a problem for urban management. The increasing numbers of urban dwellers put the demand for this scarce resource under increasing pressure, while pollution, 
Nguyen Van Thanh, et al./Vietnam Journal of Earth Sciences 39 (2017)

unsustainable economic activities, and lack of rational coastal management are main threats in particular to coastal water resources. Inventive approaches will be needed in the future preventing the use of water of lower quality, which might damage public health.

Built environment: By definition cities accumulate high amounts of materials and resources extracted by humans. Until now gathering these assets was characterized by spillage and environmental inefficiency. The city of tomorrow will be based much more on recognizing that human wellbeing requires a restored balance with nature. This needs needs to be reflected both in the green character of the urban structure and meta-management and at the level of sustainable buildings and green neighborhoods. Green cities of the future will offer a new synthesis of these complex aspects.

Ports are a most essential part of many coastal cities. They contribute to a blue economy which iss eesential in the social and economic life of port cities and their hinterland. Pollution caused mainly in the port area and off-shore can significantly be mitigated using environmental management systems aas pat of a more comprehensive environmental policy. Ports should adot a land use policy and a green environment in line with the green organization of the coastal city they are part off.

Over-all these care aspects of urban greening in the years to come show that issues related to growing (coastal) cities, including protection of the environment and adaptation to climate changes cannot be ignored, especially when it comes to dealing with the challenges discussed above. Even the analytical approach breaking down the problem in dominant factors as energy, water, buildings, green ports, and others, shows the intrinsic complexity of the problem. Each of these factors shows environmental, economic, social, organizational and policy elements which need to be aligned in a sustainable, long term way. Moreover also the integration of the domains covered by the main challenges necessitates bridges and interlinks.
This complexity can only be addressed in an interdisciplinary way, using innovative concepts (carbon negative and zero waste cities), instruments (sustainability assessment, multi criteria analysis, footprint analysis), and policies (integrated, life cycle based water management, carbon impacts in association with carbon costs and accounting). A crosscutting element in the above analysis of challenges for green cities is that each of the constituents should be approached by an interdisciplinary group of professionals: urban planners, architects, meteorologists, engineers, human ecologists, economists, and social scientists.

Next to inter-disciplinarity, a numerical approach is an essential tool for the understanding of the complex urban environment. Data varying in space and over time should contribute to systemic modelling, which merges the fragmented instruments (e.g. planning, safety, climate models) which are used today (Bosh et al., 2016).

Green urban planning integrates the physical implementation and planning aspects with health and wellbeing benefits. The extent to which a city manages to keep these different aspects under control, with a clear outlook on the future, differs. This results in different shades of green cities: From most engaged, over mainstream, to a superficiality which does not go in depth. Hai Phong is a city which recently moved in a most interesting way to green urban management. The quantification of the system using indicators provides the transition with international scientific attention (Box 4). Indicators are only one method supporting decision makers on the road to sustainable development. Other methods include urban sustainability profiles (complex interpretative description of the sustainability of an urban region and its immediate hinterland), questionnaires measuring community sustainability (dealing with a difficult process that is prone to subjectivism and lack of systemic rigor, and scenario establishment to project and simulate future trends (James, 2015). 
Cities in coastal areas might adopt integrated coastal zone management (ICZM), which started as a priority area in Europe and North America, but in spite of its limited results spreads worldwide. ICZM aims at integrating the sustainable management of oceans and coasts to maintain, restore or improve the quality of the coastal systems and their associated human societies (Olsen, 2003). This is a fundamental shift in comparison with the traditional fragmented approaches.

In port cities the sustainable integration of the port activities in the quality of the city life attracts particular attention. A well-organized environmental management system and a Port Authority optioning for Corporate Social Responsibility, is indicated dealing with the internal port management aspects. However, the port influences also the city life through its traffic generating capacity at the land side, and its responsibility for marine biodiversity, including marine protected areas, at the sea side. Establishing such a port strategy should be aligned with the stakeholders, and the city and national strategies.

Budgets allowing cities to adapt to this complexity and its intrinsic uncertainties are difficult to estimate. Storm protection and dealing with other effects of climate change on cities increasingly necessitate significant amounts of financial resourcesboth of private and public budgets (Hallegatte et al., 2013).

Future research will most likely focus on the current gaps in knowledge (e.g. on climate change impacts), and erode and quantify uncertainty, providing more appropriate and reliable frameworks to integrate the multiple aspects governing the quality of life in cities.

Box 4: Indicators used by Hai Phong, measuring the sustainability of the city.

The strategy and vision of Hai Phong on a green port city overcomes the challenges that the coastal cities are facing. The city of Hai Phong developed next to a model (Figure 4) a set of indicators for a livable city. Seven core indicator domains were selected: Air quality, water sources; waste management (solid and liquid), waste from dredging activities, noise, energy/fuel saving, pollution from the marine port activities, protection of the surrounding environment, and biodiversity in the coastal area. The city has been taken seven actions to cope with these carefully monitored indicators, including: 1 . Localize GCIF to build Green Port City Indicators (GPCI), 2. Classify the City into 4 zones for application G: Old urban, New urban, Coastal Area, Islands, 3. Cat Ba World First Learning Lab, 4. Better City Governance using a systems approach, 5. Ecological City as Economic City (Eco2), CDM, River Basin Management, Mangro For Future, 6. Management of the Islands (MPA, ICM - Integrated Coastal Management, Cat Ba GeoPark, Cat Ba Biosphere Reserve) and 7. Establish 11 green sectors by UNEP (Nguyen Van Thanh, 2014).

GCIF: Global City Indicator Facility

GPCI: Green Port City Indicators

SWOT: Strength, Weakness, Opportunities, Threats

(The model (cycle) can be explained as follows: the GCIF successfully developed an international standard on city metrics through the International Organization for Standardization (ISO) under the Technical Committee TC268 on Sustainable Development of Communities, including ISO 37120. The ISO 37120 Sustainable Development of Communities - Indicators for City Services and Quality of Life was published in May 2014 and is the first ISO international standard on city indicators. To build Green Port City of Hai Phong to meet ISO37120 and the Government green growth strategy of Vietnam, GPCI for Hai Phong is built up and then the Action plan for it is made. After a stage of the Action plan implementing, the GPCI needs to be adjust and complete to apply and monitored then evaluated to have the balancing between economic development and protection of ecosystem and environment. The last stage of the cycle is SWOT analysis for the new cycle.) 
Nguyen Van Thanh, et al./Vietnam Journal of Earth Sciences 39 (2017)

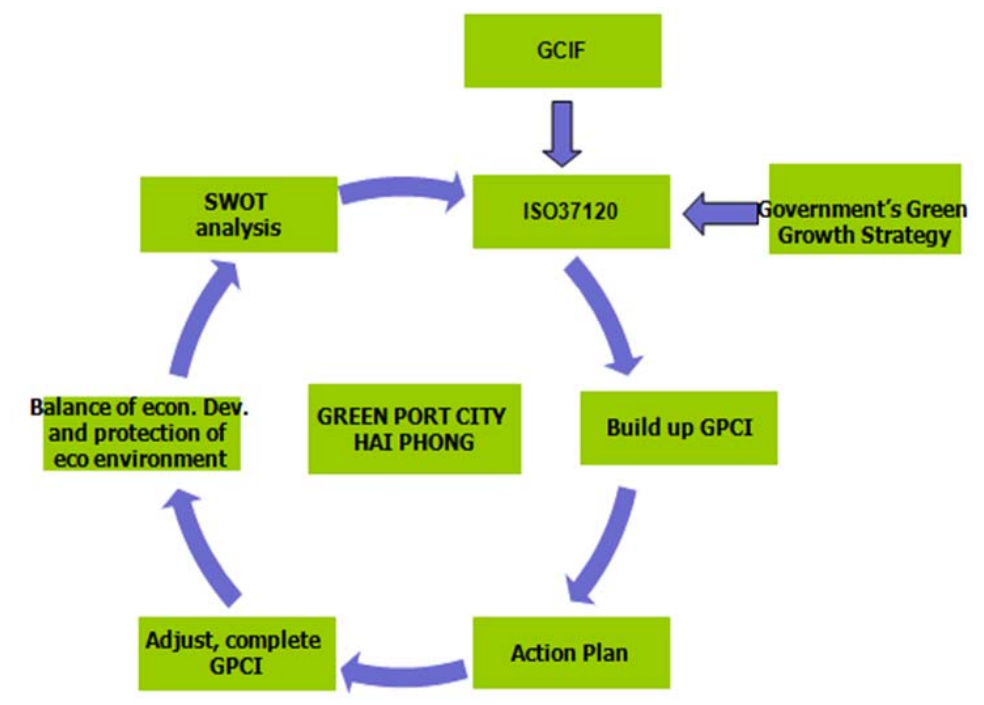

Figure 4. Green port city indicators model (Nguyen Van Thanh, 2014)

\section{Conclusions}

Cities are in quasi permanent transition. Organizing them taking into account the principles and dynamics of the urban metabolism as revealed by a greensustainable-smart-blue city approach might alleviate many problems which increased over the years. Acting on the major challenges reviewed in this paper will necessitate new processes of decision making. Instruments dealing with these challenges become gradually clearer and include:

Long term planning, including green infrastructure, systematic investment in natural areas (both on land and in the marine environment);

Cleaner technology innovations (on water treatment, low carbon emission technology, advanced waste prevention and treatment management, green roofs, and (artificial) wetlands);

Smart IT-solutions (on mobility, and trade).

The monitoring of these aspects should be structured, and the feed-back organized. These are considered essential instruments for the coming generation of decision makers in coastal cities.

\section{Acknowledgements}

This paper is based in part on the contribution of Luc Hens and Tran Dinh Lan to the "International Workshop on Public Administration of the Sea and Islands: Issues and Approaches" Hanoi, December 2 $2^{\text {nd }}, 2016$.

\section{References}

Akcin M., Kaygusuz A., Karabiber A., Alagoz S., Alagoz B.B., Keles C., 2016. Opportunities for energy efficiency in smart cities. Smart grid congress and fair (ICSG), Istanbul, Turkey. IEEE Xplore document DOI:10.1109/SGCF.2016.7492425.

Avin U., Holden D., 2000. Does your growth smart? Planning 66(1), 26-29.

Bosh O., Nguyen Nam, Nguyen Van Thanh, 2016. Systems thinking for everyone. The journey from theory to making an impact in Vietnam, pp.126. Syspac PTY Ltd., Australia.

Boulos, J., 2016. Sustainable Development of Coastal Cities-Proposal of a Modelling Framework to Achieve Sustainable City-Port Connectivity. Procedia - Social and Behavioral Sciences, 216(6), 974-985.

Camarsa G., Toland J., O’Hara E., Hudson T., Jones W., Thorpe E., Théirgnot C., 2010. LIFE and local 
Vietnam Journal of Earth Sciences, 39(2), 109-129

authorities. Helping regions and municipalities tackle environmental challenges, pp.56. Publications office of the European Union, Luxemburg.

Castro M. de Fatima, Mateus R., Braganca L., 2015. A critical analysis of buildings sustainability assessment methods for healthcare buildings. Environ. Dev. Sustain. 17, 1381-1412.

Chapple K., 2015. Planning sustainable cities and regions. Towards equitable development. pp.307. Routledge, Oxon, UK.

Childers D.L., Cadenasso M.L., Grove J.M., Marshall V., McGrath B., Pickett S.T.A., 2015. An ecology for cities: A transformational nexus of design and ecology to advance climate change resilience and urban sustainability. Sustainability 7, 3774-3791. DOI: $10.3390 /$ su 7043774 .

Colombo R., 2016. Unpreceded rise in cities disclosing climate strategies.pp.3. Raffaella.colombo@cdp.net.

Dasgupta S., Lapla B., Murray S., Wheeler D., 2009. Sea-level rise and storm surges: A comparative analysis of impacts in developing countries. World Bank Policy Research Working Paper (42) WPS4901. World Bank, Washington DC.

De Las Heras A., 2014. Sustainability science and technology. An introduction, 322pp. CRC Press, Taylor and Francis Group, Boca Roca, Fl.

Diaz P., Stanek P., Frantzeskaki N., Yeh D., 2016. Shifting paradigms, changing waters: Transitioning to integrated urban water management in the coastal city of Dunedin, USA. Sustainable Cities and Society 26, 555-567.

Do Thi Thu Huong, Tran Dinh Lan, 2014. Da Nang Ports. In: Environmental management of seaports in Vietnam. Tran Dinh Lan, Luc Hens, Cao Thi Thu Trang, Do Thi Thu Huong Eds., pp.316. Publishing House for Science and Technology, Hanoi, Vietnam.

Duhem B., 2005. Introduction. In: Green structure and urban planning. Final report, pp.13-14.A.C. Werquin, B. Duhem, G. Lindholm, B. Oppermann, S. Pauleit, S. Tjallingii Eds. Office for Official publications of the European Communities. Luxemburg.

Duong Thanh Nhi, Chu The Cuong, Tran Dinh Lan, 2014. The ports of Hai Phong. In: Environmental management of seaports in Vietnam. Tran Dinh Lan,
Luc Hens, Cao Thi Thu Trang, Do Thi Thu Huong Eds., 177-219. Publishing House for Science and Technology, Hanoi, Vietnam.

Giffinger R., Fertner C., Kramar H., Kalasek R., 2007. Smart cities: ranking of European medium-sized cities. Vienna University of Technology, Vienna, Austria.

Godschalk D.R., 2007. Land use planning challenges: Coping with conflicts in visions of sustainable development and livable communities. Journal of the American Planning Association 70(1), 5-13, DOI: 10.1080/01944360409876334.

Griggs D., Stafford-Smith M., Gaffney O., Rockström J., Öhman M.C., Shyamsundar P., Steffen W., Glaser G., Kanie N., Noble I., 2013. Policy: Sustainable development goals for people and planet. Nature 495, 305-307.

Haase, D., 2015. Reflections about blue ecosystem services in cities. Sustainability of Water Quality and Ecology 5, 77-83.

Hallegate S., Green C., Nicholls R.J., Corfee-Morlot J., 2013. Future flood losses in major coastal cities. Nature Climate Change 3, 802-806.

Hassan A.M., Lee H., 2015. The paradox of the sustainable city: Definition and examples. Environ. Dev. Sustain. 17, 1267-1285.

Henn R., Hoffman A.J., 2013. Constructing green. The social structures of sustainability. pp.398. MIT Press, Cambridge, Ma.

Hinrichsen D., 1998. Coastal waters of the world. Trends, threats, and strategies. pp.275. Island Press, Washington DC.

Hoekstra A. Y., Chapagain A. K., 2007. Water footprints of nations: Water use by people as function of their consumption pattern. Water Resources Management 21, 35-48.

Huang G.L., Zhou W.Q., Cadenasso M.L., 2011. Is everyone hot in the city? Spatial pattern of land surface temperatures, land cover and neighborhood socioeconomic characteristics in Baltimore M.D. J. Environ. Manag, 92, 1753-1759.

IDF-International Diabetes Federation, 2015. IDF atlas, $7^{\text {th }}$ ed. Brussels, Belgium.

IPCC-Intergovernmental Panel on Climate Changes, 2007. Climate change 2007 - Impacts, adaptation, 
Nguyen Van Thanh, et al./Vietnam Journal of Earth Sciences 39 (2017)

and vulnerability. Contribution of working group III to the fourth assessment report of the IPCC. Cambridge University Press, NY.

IPCC-Intergovernmental Panel on Climate Changes, 2014. Climate change 2014. Synthesis ReportLonger report, pp.116. United Nations, New York.

James P., 2015. Urban sustainability in theory and practice. Circles of sustainability, pp.260. Earthscan from Routledge, Oxon, UK.

Jung H.S., Jeong C.S., Lee Y.W., et al., 2009. An intelligent ubiquitous middleware for U-city: Smart UM. Journal of Information Science and Engineering 25, 375-388.

Kabisch N., Strohbach M., Haase D., Kronenberg J., 2016. Urban green space availability in European cities. Ecological Indicators 70, 586-596.

Kennedy S., Sgouridis S., 2011. Rigorous classification and carbon accounting principles for low and Zero Carbon Cities. Energy Policy 39, 5259-5268.

Khazaei, M., Razavian, M.T., 2013. Sustainable Urban Development (an innovative approach in the development of cities around the world). International Research Journal of Applied and Basic Sciences 4, 1543-1547.

Le Xuan Quynh, 2014. Environmental management system in ports. In: Environmental management of seaports in Vietnam. Tran Dinh Lan, Luc Hens, Cao Thi Thu Trang, Do Thi Thu Huong Eds, pp.115-148. Publishing House for Science and Technology, Hanoi, Vietnam.

Luccarelli M., Roe P.G. (Eds.), 2012. Green Oslo. Visions, planning and discourse. Ashgate, Farnham, UK.

Malcolm L., 2004. Integrated design for sustainable buildings. ASHRAE Journal 46, S22-S26, S28-S30. For the summer performance assessment of extensive green roofs in a Mediterranean coastal climate. Energy and Buildings 63, 1-14.

Mnowlton K., Lynn R., Goldberg R.A., Hogrefe C., Rosenthal J., Kinney P.L., 2007. Projecting healthrelated mortality impacts under a changing climate in the New York City region. Am. J. Public Health 07, 2028-2034.

MONRE-Ministry of Natural resources and Environment, 2012. Climate change and sea level rise scenarios for Vietnam. Hanoi, Vietnam.
MONRE-Ministry of Natural Resources and Environment, 2015. State Report of Environment 2011-2015, Hanoi, Vietnam.

Mueller N., Rojas-Rueda D., Basagana X., Cirach M., Cole-Hunter T., Dadvand P.,Donaire-Gonzalez D., Foraster M., Gascin M., Martinez D., Tonne C., Triguero-Mas M., Valentin A., Niewenhijsen M., 2016. Urban and transport planning related exposures and mortality: A health impact assessment for cities. Environmental Health Perspectives. DOI: $10.1289 /$ EHP220. Also available at http://ehp.niehs.nih.gov/eph220/.

Neirott P., De Marco A., Cagliano A.C., Mangano G., Scorrano F., 2014. Current trends in smart city initiatives: Some stylised facts. Cities 38, 25-36.

Nguyen Van Thang, Nguyen Trong Hieu, Tran Thuc, Pham Thi Thanh Huong, Nguyen Thi Lan, Vu Van Thang, 2011. Climate change and its impacts in Vietnam. Science and Technology Publishing House, Hanoi, Vietnam, 259pp (in Vietnamese).

Nguyen Van Thanh, 2014. Applying GCIF \& ISO37120 for Building Hai Phong Green Port City. Report at the London Conference, 17-18 Nov. 2014.

Olivien F., Di Pema C., D’Orazio M., Olivien N., Neila J., 2013. Experimental measurements and numerical model for the summer performance assessment of extensive green roofs in a Mediterranean coastal climate. Energy and Buildings, 63, 1-14.

Olsen S.B., 2003. Frameworks and indicators for assessing progress in integrated coastal management initiatives. Ocean \& Coastal Management 46, 347-361.

Schnitzer H. Resource efficient and clean urban technologies, 2015. In Gianetti B.F., Almeida C.M.V.B., Agostinho F., Bonilla S.H. Eds. Advances in Cleaner Production. Proceedings of the $5^{\text {th }}$ International Workshop, UNIP, Sao Paulo, SP, Brazil. May $20^{\text {th }}-22^{\text {nd }}, 2015$, p. 20 .

Taghvaei, M., 2013. Urban sustainable development and the factors affecting it (Case Study: Kermanshah). Urban Sociological Studies 3, 1-22.

Tran Dinh Lan, Luc Hens, Cao Thi Thu Trang, Do Thi Thu Huong, 2014. Environmental management of seaports in Vietnam, pp.316. Publishing House for Science and Technology, Hanoi, Vietnam. 
Vietnam Journal of Earth Sciences, 39(2), 109-129

Ülpre H., Eames I., 2014. Environmental policy constrains for acidic exhaust gas scrubber discharges from ships. Marine Pollution Bulletin 88, 292-301. DOI: 10.1016/j.marpobul.2014.08.027.

UNDP-United Nations Development Programme, 2007. Fighting climate change: Human solidarity in a divided world. Human Development Report 2007/2008. United Nations, NY.

UN-United Nations, 1992. Agenda 21: The United Nations Programme of Action from Rio. United Nations, New York. Available on line at http//www.un.org/esa/dsd/agenda21/res_agenda21_0 0. shtm (last accessed November 11th, 2016).

UN-Habitat, 2009. Planning sustainable cities. Global report on human settlements 2009, pp.306. Earthscan, Sterling, Va.

Upton S., 2015. Organisation for Economic Cooperation and Development. The OECD Observer, suppl. OECD Yearbook 2015 (Jun 2015), 64-65.

Vadineanu A., 2001. Sustainable development: Theory and practice regarding the transition of socioeconomic systems towards sustainability, pp.304. Tip Art Group Publishing and Printing Company, Bucharest, Romania.

Vardoulakisq E., Koromanis B., Fotiadi A., Mihalakakov G., 2013. The urban heat island effect in a small Mediterranean city of high summer temperatures and cooling energy demands. Solar Energy 94, 128-144.
Varol, C., Ercoskun, O., Gurer, Y., 2010. Local participatory mechanisms and collective actions for sustainable urban development in Turkey. Habitat International 35, 9-16.

Vu Thanh Ca, Du Van Toan, Nguyen Van Tien, Nguyen Hoang Anh, Nguyen Hai Anh, Tran The Anh, Vu Thi Hien, 2010. Some preliminary results and numerical model for inundation calculation of Haiphong coastal area in the climate change and sea level rise. Journal of Marine Science and Technology, 10(2), 45-62.

Vu Van Hieu, Le Xuan Quynh, Pham Ngoc Ho, Hens L., 2013. Application of GIS and modeling in health risk assessment for urban road and mobility. Environ. Sci. Pollut. Res. 20, 5138-5149, DOI: 10.1007/s11356-013-1492-5.

WB-World Bank, 2010. Natural hazards, unnatural disasters: The economics of effective protection. International Bank for Reconstruction and Development. World Bank Publications, Washington DC.

WHO-World Health Organization, Regional Office for Europe, 2016. Towards environmentally sustainable health systems in Europe. A review of the evidence. Publications of the WHO Regional Office for Europe, Copenhagen, Denmark.

Zlender V., Thompson C. W., 2016. Accessibility and use of peri-urban green space for inner-city dwellers: A comparative study. Landscape and Urban Planning, in press. 